\title{
Effects of Cryogenic Forging and Anodization on the Mechanical Properties and Corrosion Resistance of AA6066-T6 Aluminum Alloys
}

\author{
Teng-Shih Shih ${ }^{1, *}$, Hwa-Sheng Yong ${ }^{1,2}$ and Wen-Nong Hsu ${ }^{1,2}$ \\ 1 Department of Mechanical Engineering, National Central University, Jhongli District, Taoyuan City 32001, \\ Taiwan; nite-star@hotmail.com (H.-S.Y.); nong88@yam.com (W.-N.H.) \\ 2 Graduate Student, National Central University, Jhongli District, Taoyuan City 32001, Taiwan \\ * Correspondence: t330001@cc.ncu.edu.tw; Tel.: +886-3-4267317; Fax: +886-3-4254501
}

Academic Editor: Nong Gao

Received: 11 December 2015; Accepted: 23 February 2016; Published: 3 March 2016

\begin{abstract}
In this study, AA6066 alloy samples were cryogenically forged after annealing and then subjected to solution and aging treatments. Compared with conventional 6066-T6 alloy samples, the cryoforged samples exhibited a $34 \%$ increase in elongation but sacrificed about $8 \%-12 \%$ in ultimate tensile strength (UTS) and yield stress (YS). Such difference was affected by the constituent phases that changed in the samples' matrix. Anodization and sealing did minor effect on tensile strength of the 6066-T6 samples with/without cryoforging but it decreased samples' elongation about $8 \%-10 \%$. The anodized/sealed anodic aluminum oxide (AAO) film enhanced the corrosion resistance of the cryoforged samples.
\end{abstract}

Keywords: cryoforging; anodization; tensile properties; corrosion resistance

\section{Introduction}

$\mathrm{Al}-x \mathrm{Mg}-y \mathrm{Si}$ alloys (6xxx series $\mathrm{Al}$ alloys) are commonly used as extruded shapes and forged for making bicycle parts. Their characteristics include ample formability, machinability, weldability, and corrosion resistance, as well as good strength and elongation after heat treatment. These alloys are also readily available on the market.

Aluminum possesses a high stacking fault energy and readily undergoes dynamic recovery during deformation. Plastic deformation at low temperatures, such as cryorolling, is beneficial for refining grains in an aluminum alloy matrix [1,2]. Chen studied equal-channel deformation of an Al-Mg alloy at cryogenic temperatures and found that high-density dislocations distorted grains to a refining grain size [3]. Lee et al. also found that cryorolling 5083 alloy could obtain $200 \mathrm{~nm}$ fine grains to increase the ultimate tensile strength (UTS) from 315 to $522 \mathrm{MPa}$ [4]. For an Al-Mg-Si alloy, cryorolling with a 90\% reduction could cause heavy plastic deformation to produce nanosized extra-fine grains [5-7].

Aluminum alloys that become deformed at cryogenic temperatures could suppress the dynamic recovery that occurs during plastic deformation, and could acquire fine grains featuring high-angle grain boundaries $[8,9]$. The interaction of high-density dislocations enhanced the precipitation capability for producing a high density of nanosized precipitates [10]. Yin et al. found nanograins that were less than $500 \mathrm{~nm}$ in size in 7075 alloy samples subjected to compression forging at cryogenic temperatures [11].

Krishina et al. [8,12] produced ultrafine-grained $\mathrm{Al}-4 \mathrm{Zn}-2 \mathrm{Mg}$ alloys by cryorolling and indicated that the driving force for precipitation could be enhanced by differential scanning calorimetry. As a result, the precipitates of the $\eta$ phase became finer compared with conventional aging treatment. Sarma [13] found that cryorolling significantly changed aging behavior, leading to a reduction 
in the aging temperature from 190 to $125{ }^{\circ} \mathrm{C}$ and in aging time from 24 to $8 \mathrm{~h}$ for treating 2219 alloy (Al-Cu alloy).

Jayaganthan [14] used X-ray analyses to study the aging behavior of 6061 alloy subjected to solution treatment then cryorolling. They found that increasing true strain in cryorolling tended to enhance the dissolution of alloys in the alloy matrix and promoted the driving force for precipitation. The UTS was improved from 300 to $365 \mathrm{MPa}$ and elongation was raised from $11 \%$ to $13 \%$. Cryorolling apparently reduced the size of intermetallic compounds contained in the matrix of 7075-T73 alloys. As a result, the corrosion resistance of anodized and sealed 7075-T73 alloy could be significantly enhanced [15].

Anodization and sealing improves the corrosion resistance of $\mathrm{Al}$ alloys by forming amorphous alumina and hydrate alumina in the anodized film. This process has been widely used in industry. Forging is a common process used for making bicycle and automobile parts. Determining the influence of cryoforging on the corrosion resistance of $\mathrm{Al}$ alloys with or without anodization should provide more values for designing and using $\mathrm{Al}$ alloys.

Copper was added as an alloying element in a $6 x x x$ series alloy to enhance mechanical strength by precipitation hardening after heat treatment. For example, $6066 \mathrm{Al}$ alloy contains some high-strength $\mathrm{Cu}(0.8-1.4 \mathrm{Mg}, 0.9-1.8 \mathrm{Si}, 0.6-1.1 \mathrm{Mn}$, and $0.7-1.2 \mathrm{Cu})$ to obtain a UTS of $393 \mathrm{MPa}$ and a yield stress (YS) of $359 \mathrm{MPa}$ after a T6 treatment. This study introduced cryoforging to further improve the toughness of 6066-T6 alloys and their corrosion resistance. The effects of anodization and sealing on the tensile properties and corrosion resistance of AA6066-T6 with and without cryoforging were also evaluated.

\section{Experimental Procedures}

\subsection{Materials}

As-extruded 6066 alloy bars, $\varnothing 42 \times 100 \mathrm{~mm}$ in size, were supplied by Tzan Wei Aluminum Co., Ltd. (Tainan, Taiwan). The chemical compositions of the alloys (in wt. \%) were $1.38 \mathrm{Si}, 0.15 \mathrm{Fe}, 1.18 \mathrm{Cu}$, $1.00 \mathrm{Mn}, 1.09 \mathrm{Mg}, 0.16 \mathrm{Cr}, 0.04 \mathrm{Zn}$, and $0.02 \mathrm{Ti}$.

After annealing at $688 \mathrm{~K}$ for $120 \mathrm{~min}$, the samples were divided into two groups. The first group was subjected to a solution treatment ( $803 \mathrm{~K}$ for $120 \mathrm{~min}$ ) and artificial aging ( $450 \mathrm{~K}$ for $480 \mathrm{~min}$ ); these samples were coded as T6 samples. The second group was subjected first to cryogenic forging, achieving a $40 \%$ reduced thickness (from 28 to $16.8 \mathrm{~mm}$ ), then immersed in liquid nitrogen again, rotated by $90^{\circ}$, and subjected to a second round of cryogenic forging. A 500-ton hydraulic press equipped with one open die set was used to conduct compression forging. After forging, the second group of samples was subjected to the solution to get CFT4 sample and followed by artificial aging treatments: $450 \mathrm{~K}$ for $480 \mathrm{~min}$ for CFT6a samples and $540 \mathrm{~min}$ for CFT6b samples.

\subsection{Tensile and Fatigue Tests}

The specimens used for testing tensile and rotating bending fatigue strengths were machined from heat-treated samples according to the ASTM B557 [16] (gage diameter: $6 \mathrm{~mm}$ ) and JIS Z2274 [17] (gage diameter: $8 \mathrm{~mm}$ ) specifications as shown in Figure 1a,b. The machined test bars were polished by a series of abrasive papers ( 2000 grit) and an alumina slurry to achieve a surface roughness of less than $0.1 \mu \mathrm{m}(R a)$. 


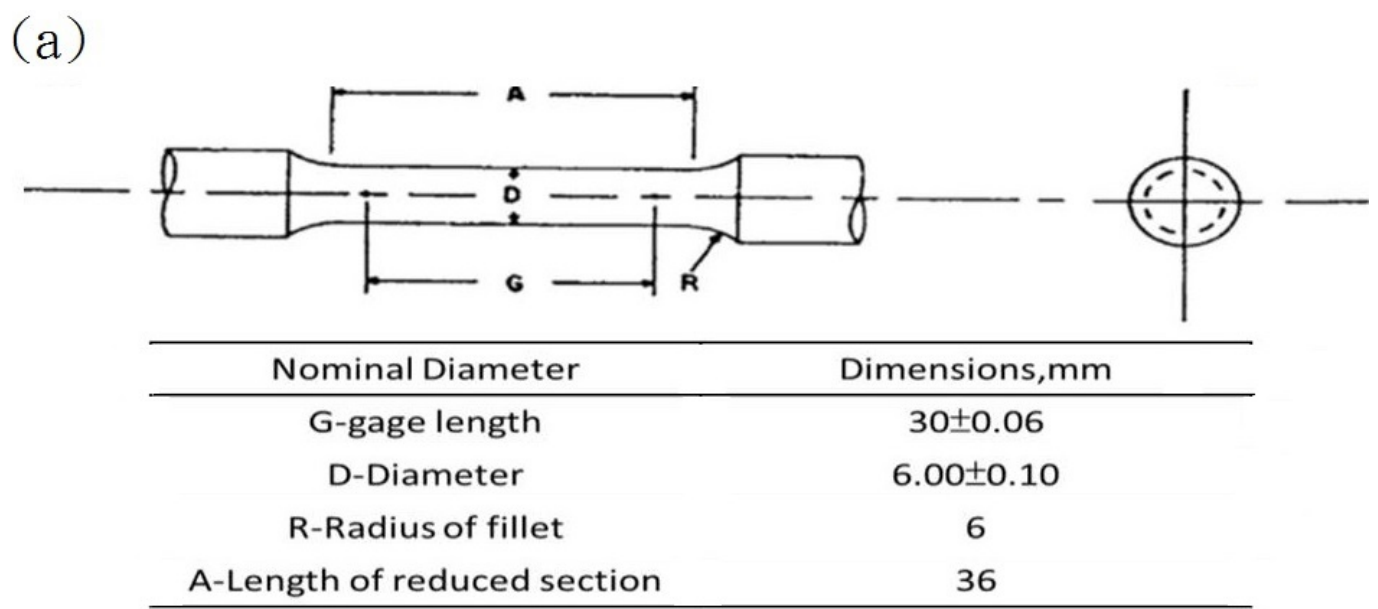

(b)

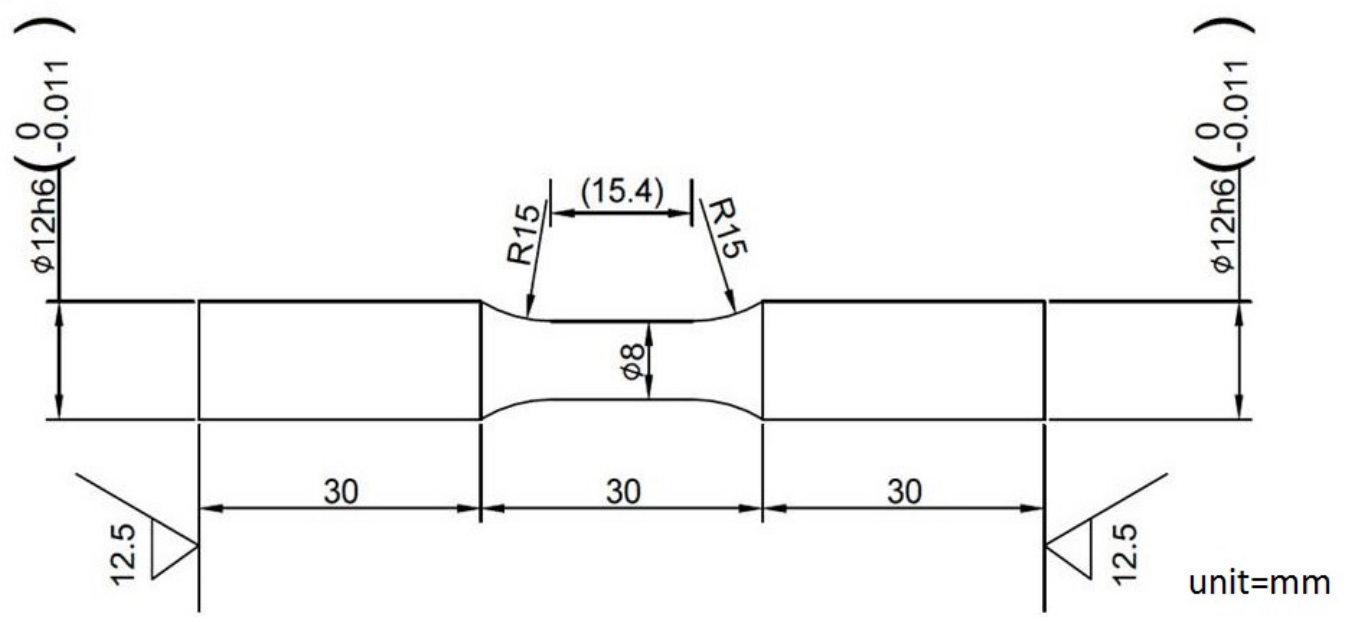

Figure 1. The dimensions of specimens used for (a) tensile test (gage diameter: $6 \mathrm{~mm}$ ); and (b) rotating bending test (gage diameter: $8 \mathrm{~mm}$ ).

\subsection{X-ray Tests}

X-ray diffraction (XRD) measurements were performed by using a NANO-Viewer Advance (Rigaku, Tokyo, Japan) equipped with a $\mathrm{Cu}$ target to identify the precipitates (or second-phase particles) formed in the matrix of different samples, including the T6, CFT4, and CFT6a samples. The cryoforged samples were solution-treated to get a CFT4 sample and followed by aging treatment to acquire a CFT6a sample. A power of $30 \mathrm{KV}$ and current of $10 \mathrm{~mA}$ were used in this study. The sample sizes were $10 \times 10 \times 1 \mathrm{~mm}$.

\subsection{Anodization Process}

Before anodization, all samples were polished to a surface roughness of approximately $R a \leqslant 0.1 \mu \mathrm{m}$ and then dipped into methanol and ultrasonically vibrated. The specimens were initially degreased by immersion in an alkaline solution ( 5 mass $\% \mathrm{NaOH})$ at $60{ }^{\circ} \mathrm{C}$ for $30 \mathrm{~s}$ and were then rinsed with water for 1-2 min. For the pickling process, specimens were submerged in an aqueous solution of $\mathrm{HNO}_{3}(30 \mathrm{vol}$. \%) for $90 \mathrm{~s}$ at room temperature and then rinsed with water for 1-2 min. The anodization was conducted at $15 \mathrm{~mA} \cdot \mathrm{cm}^{-2}$ at $15{ }^{\circ} \mathrm{C}$ for $900 \mathrm{~s}$ in a 15 mass \% sulfuric acid solution. The anodized samples were sealed in hot water at $95^{\circ} \mathrm{C}$ for $1200 \mathrm{~s}$ [18]. After anodization, scanning electron microscopy was conducted and determined that the anodic film was 12-14 $\mu \mathrm{m}$ thick. The anodized samples were sealed in hot water at $368 \mathrm{~K}$ for $20 \mathrm{~min}$. 


\section{Results and Discussion}

\subsection{Microstructure Observation and Tensile Properties}

Table 1 shows the measured mechanical properties of different samples. The CFT6b samples, which aged for 60 min longer than did the CFT6a samples, had increased strength but reduced elongation. The CFT6a samples exhibited a similar strength but superior elongation to the CFT6b samples, and they were adopted in this study for evaluation of their corrosion resistance and fatigue strength. In addition, the CFT6a samples obtained a matrix with a uniform hardness (HV minimum deviation: 1.7$)$.

Table 1. Mechanical properties of T6, CFT6a and CFT6b samples.

\begin{tabular}{ccccc}
\hline \multirow{2}{*}{ Sample } & \multicolumn{3}{c}{ Tensile Strengths } & \multirow{2}{*}{ Vickers Hardness (HV) } \\
\cline { 2 - 4 } & UTS (MPa) & YS (MPa) & Elongation (\%) & \\
\hline T6 & $460(0.5)$ & $438(1.4)$ & $10.6(1.7)$ & $133.6(2.9)$ \\
CFT6a & $431(6.6)$ & $394(9.2)$ & $14.2(0.2)$ & $136.6(1.7)$ \\
CFT6b & $435(5.4)$ & $404(10.1)$ & $13.4(0.9)$ & $137.1(2.9)$ \\
\hline \multicolumn{5}{c}{ Note: the deviations are listed in parentheses. }
\end{tabular}

Figure 2a,b show the second-phase (SP) and/or intermetallic compounds (IMC) located at the cross-sections in the transverse direction of the T6 and CFT6a samples. Different sizes of particles were counted and are listed in Table 2. The T6 samples exhibited more coarse SP/IMC particles than the CFT6a samples did as revealed by arrows in Figure 2. During the cryogenic forge, a shear stress was generated to act on the samples' matrix, breaking down the particles. As a result, the particles became finer and dissolution was enhanced during the solution treatment. The total SP/IMC particle count decreased from 864 to 734 counts $/ \mathrm{mm}^{2}$.

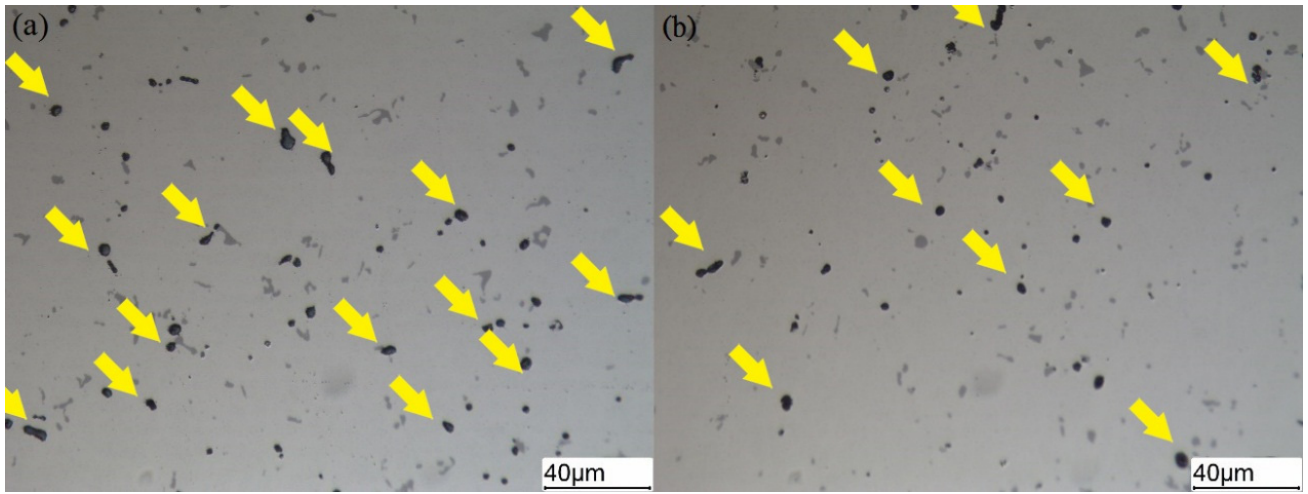

Figure 2. Optical micrographs show second-phase particles located in the matrix of (a) T6; (b) CFT6a sample; non-etched cross-section in transverse direction.

Table 2. The SP and/or IMC particles measured from T6 and CFT6a samples; maximum particle size and count population were included.

\begin{tabular}{cccccc}
\hline \multirow{2}{*}{ Sample } & \multicolumn{2}{c}{ Second Phase (Coarse Precipitates) Counts $/ \mathbf{m m}^{\mathbf{2}}$} & \multirow{2}{*}{ Max. Diameter of Particle, $\mu \mathbf{m}$} \\
\cline { 2 - 4 } & $\mathbf{1 - 1 0}$ & $\mathbf{1 1 - 2 0}$ & $\mathbf{> 2 0}$ & Total Count & \\
\hline T6 & 838 & 25 & 0 & 864 & 17 \\
CFT6a & 719 & 15 & 0 & 734 & 17 \\
\hline
\end{tabular}

Electron backscattered diffraction (SUPRA ULTRA 55 field emission scanning electron microscope, ZEISS, Jena, Germany) was performed to measure the misorientation angles of grain boundaries in the 
longitudinal direction of the tensile test bar samples, as illustrated in Figure 3a,b for the CFT6a and T6 samples, respectively. The CFT6a sample had a high fraction of high-angle grain boundaries (HAGBs). The matrix of the T6 sample had grains featuring mainly low-angle grain boundaries, as shown in Figure 3b. The cyclic loaded sample after being subjected to $250 \mathrm{MPa}$ and fractured at $2.56 \times 10^{5}$ life cycles is shown in Figure 3c, revealing further increasing HAGBs compared with those in Figure 3a. This increase could have been affected by dynamic recrystallization during cyclic loading.
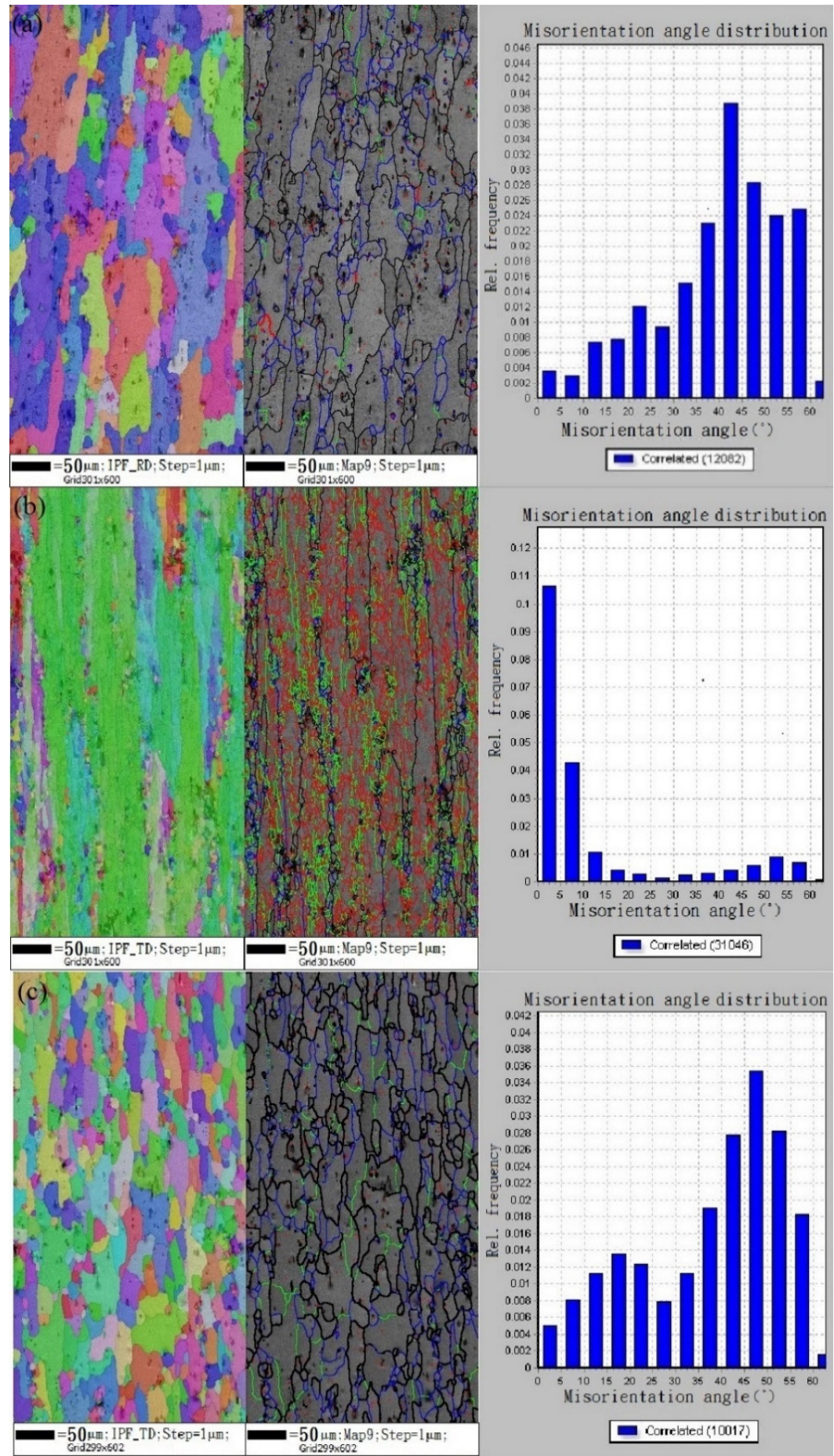

Figure 3. Inverse pole figure maps obtained from EBSD data and measured misorientation angle of grain boundaries from (a) CFT6a tensile tested sample; (b) T6 tensile tested sample; and (c) CFT6a sample after subjected to $250 \mathrm{MPa}$ and fractured at $2.56 \times 10^{5}$ life cycles. 
The T6 sample comprised $\alpha-\mathrm{Al}, \mathrm{Q}-(\mathrm{AlCuMgSi}), \mathrm{Al}(\mathrm{Mn}, \mathrm{Fe}) \mathrm{Si}$, and some $\mathrm{Mg}_{2} \mathrm{Si}$ phases, as shown in Figure 4. After solution treatment, the cryoforged sample was tested and indicated that SP/IMC particles were highly dissolved in its matrix, as confirmed by the CFT4 sample in Figure 4. After artificial aging, the intensity of the $Q$ phase was notably decreased, presenting complex phases of $\mathrm{Mg}_{2} \mathrm{Si}, \mathrm{Q}-(\mathrm{AlCuMgSi})$, and $\mathrm{Al}(\mathrm{Mn}, \mathrm{Fe}) \mathrm{Si}$, as well as some $\mathrm{Cu}_{9} \mathrm{Al}_{4}$ and $\mathrm{CuMgSi}$ phases; see CFT6a sample. Kim et al. annealed copper wire and an aluminum pad at 150 to $300^{\circ} \mathrm{C}$ and found a $\mathrm{Cu}_{9} \mathrm{Al}_{4}$ phase with an X-ray spectra peak at $43.9^{\circ}$ [19].

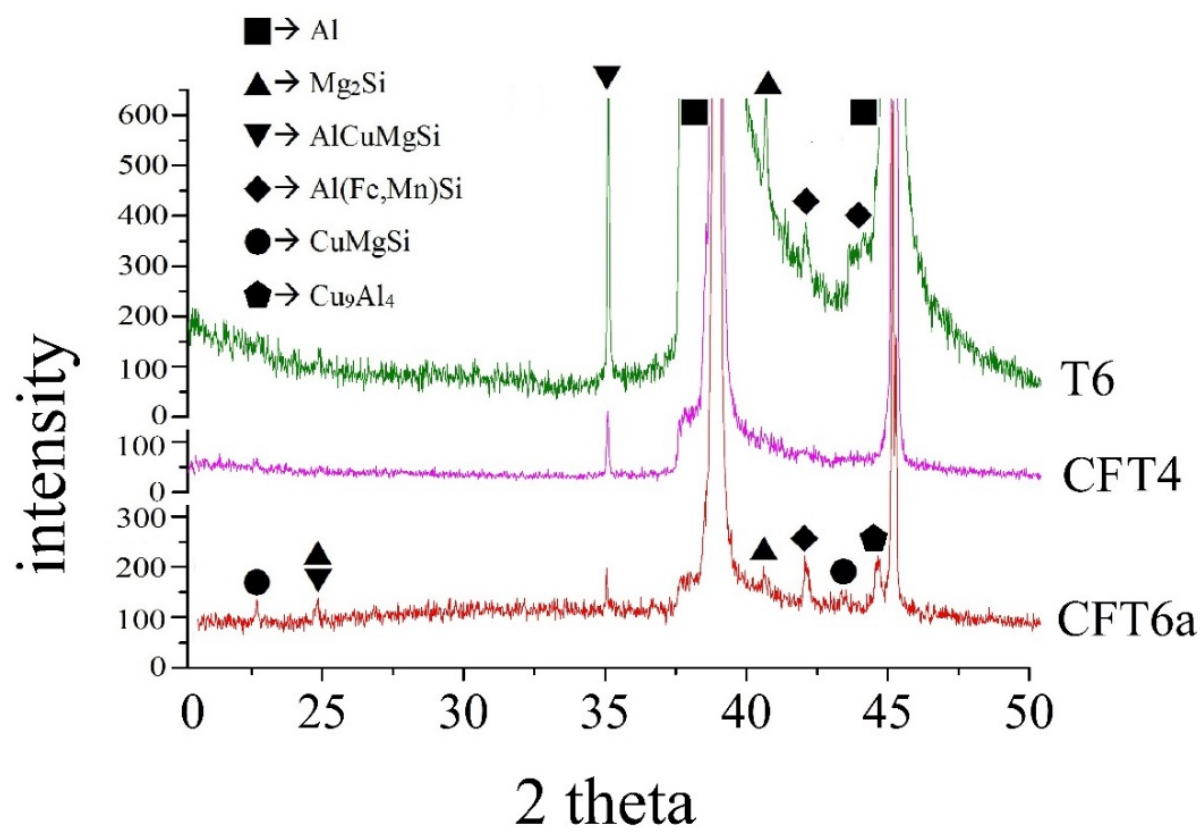

Figure 4. XRD patterns of 6066 alloy samples; including solution and aging T6 sample; cryoforged samples after solution treatment CFT4 and aging CFT6a, respectively.

The diffusivity of alloying elements in the aluminum matrix is in the order of $D_{\mathrm{Cu}} / \mathrm{Al}$ $\left(4.44 \times 10^{-5} \mathrm{~m}^{2} / \mathrm{s}\right), D_{\mathrm{Mg} / \mathrm{Al}}\left(1.49 \times 10^{-5} \mathrm{~m}^{2} / \mathrm{s}\right)$, and $D_{\mathrm{Si} / \mathrm{Al}}\left(1.38 \times 10^{-5} \mathrm{~m}^{2} / \mathrm{s}\right)$ in face-centered cubic $\mathrm{Al}$ [20]. $\mathrm{Cu}$ atoms tend to segregate around the metastable phase in the $\mathrm{Al}-\mathrm{Mg}-\mathrm{Si}$ alloy, move to grain boundaries during the solution treatment, and diffuse to $\mathrm{Mg}-\mathrm{Si}$ nanoparticles located at or near grain boundaries to finally form type-C precipitates [21] and the $Q$ phase [22]. As a result, in this study, the T6 sample mainly contained the $Q$ phase and $\mathrm{Mg}_{2} \mathrm{Si}$ precipitates after aging. The present XRD spectra did not detect the $S-\mathrm{Al}_{2} \mathrm{CuMg}$ phase from the T6 sample. Neither could Vieira find the $\mathrm{S}-\mathrm{Al}_{2} \mathrm{CuMg}$ phase in his study, in which two age-hardening heat treatments of $\mathrm{Al}-10 \mathrm{Si}-4.5 \mathrm{Cu}-2 \mathrm{Mg}$ were completed [23].

The CFT6a sample increased the HAGBs in its matrix to provide more potent sites for accommodating $\mathrm{Cu}$ atoms after the solution treatment. During quench or aging in room temperature, $\mathrm{Cu}$ diffused to tie up with $\mathrm{Al}$ forming $\mathrm{Cu}_{9} \mathrm{Al}_{4}$ phase. During artificial aging, a $\mathrm{Mg}-\mathrm{Si}$ cluster formed in situ; this either led to the formation of CuMgSi precipitates through movement of the $\mathrm{Cu}$ atoms, or the $\mathrm{Cu}-\mathrm{Mg}$ clusters formed first and subsequently incubated the CuMgSi precipitate in the matrix. Figure 5a,b shows the transmission electron microscopy photos of the T6 and CFT6a samples, respectively. For a given solution and aging conditions, the CFT6a sample achieved finer precipitates (less than $100 \mathrm{~nm}$ ) than the T6 sample did. The main constituted phases likely included $\mathrm{Al}(\mathrm{Mn}, \mathrm{Fe}) \mathrm{Si}$ in block and plate shapes, and some fine particles (less than $100 \mathrm{~nm}$ ) likely being $\mathrm{Cu}_{9} \mathrm{Al}_{4}$ and $\mathrm{CuMgSi}$ precipitates or $\mathrm{Cu}$ atoms surrounding fine $\mathrm{Mg}_{2} \mathrm{Si}$ phases, as shown in Figure $5 \mathrm{~b}$. The $\alpha-\mathrm{Al}(\mathrm{Mn}, \mathrm{Fe}) \mathrm{Si}$ dispersoids could have a block-shaped or plate-shaped morphology in the size of 50-200 nm, as reported by Li et al. [24]. 


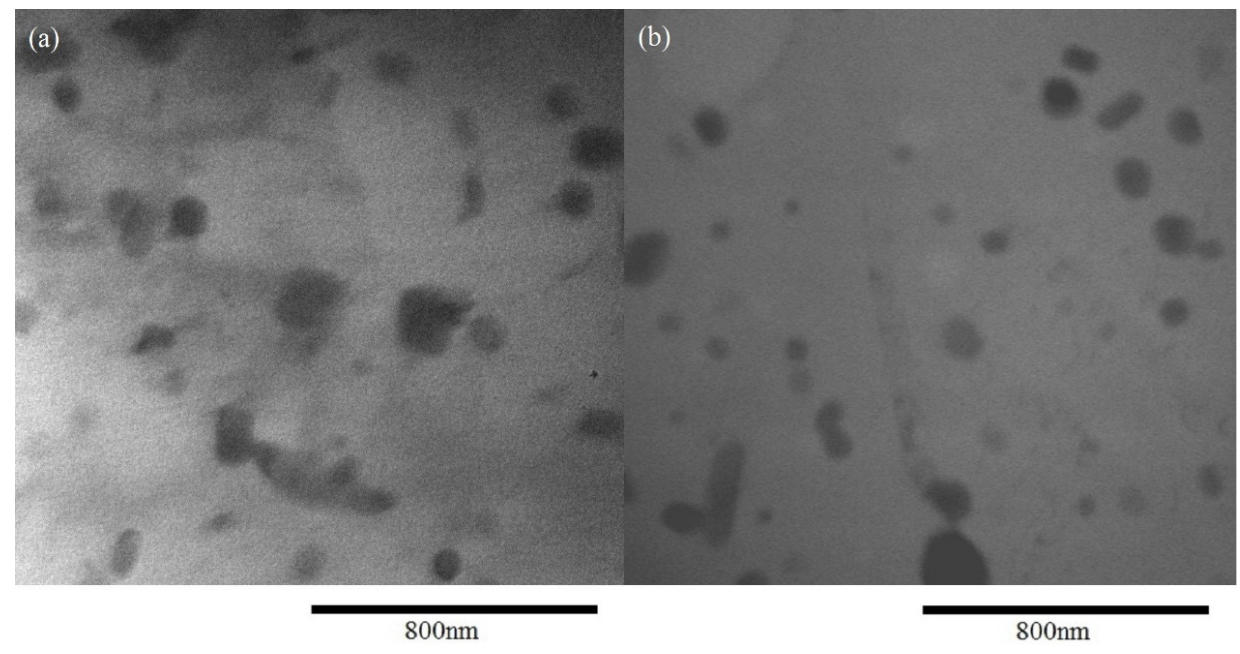

Figure 5. TEM photo show the plate-shape and lump-shape precipitate in the matrix of (a) T6 sample, and (b) CFT6a sample.

An electron probe X-ray microanalyzer (JXA-8200, JEOL USA, Inc., Peabody, MA, USA) was used to obtain images of $\mathrm{Mg}, \mathrm{Si}, \mathrm{Mn}$, and $\mathrm{Cu}$ mappings from the matrix of the CFT6a sample. The white aggregates in Figure 6a are the $\mathrm{Al}(\mathrm{Mn}, \mathrm{Fe}) \mathrm{Si}$ and $Q$ phase, and the black lumps are $\mathrm{Mg}_{2} \mathrm{Si}$ particles. The arrows indicate the locations of $Q$-phase precipitates. The $\mathrm{CuMgSi}$ and $\mathrm{Cu}_{9} \mathrm{Al}_{4}$ precipitates are nanoscale and were difficult to detect by mapping. In Figure $6 \mathrm{~b}$, the white particles shown in the matrix of the T6 samples are $\mathrm{Al}(\mathrm{Mn}, \mathrm{Fe}) \mathrm{Si}$ and $\mathrm{Q}-\mathrm{AlCuMgSi}$ phases. An $\mathrm{Al}(\mathrm{MnFe}) \mathrm{Si}$ particle attached with $\mathrm{Cu}$ atoms could be distinguished and are indicated by an arrow. The black spots are the $\mathrm{Mg}_{2} \mathrm{Si}$ phase.

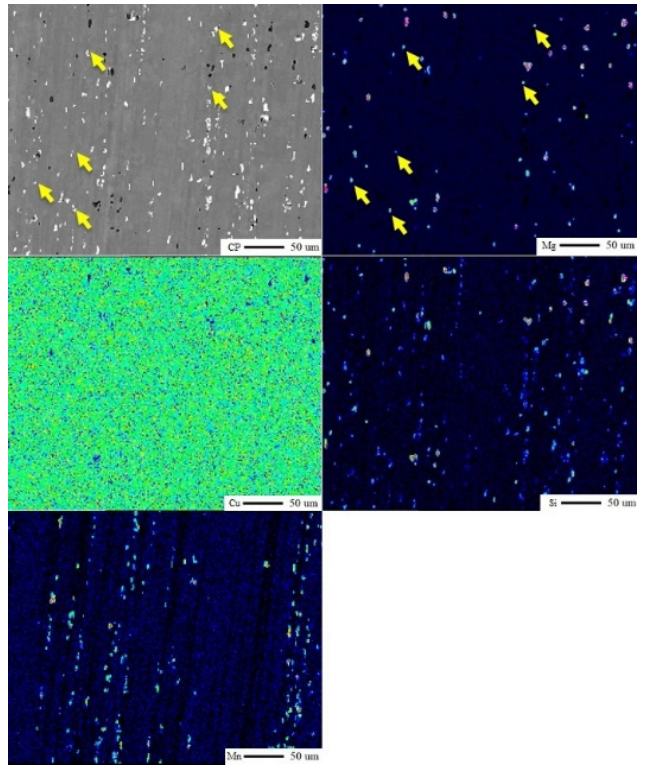

(a)

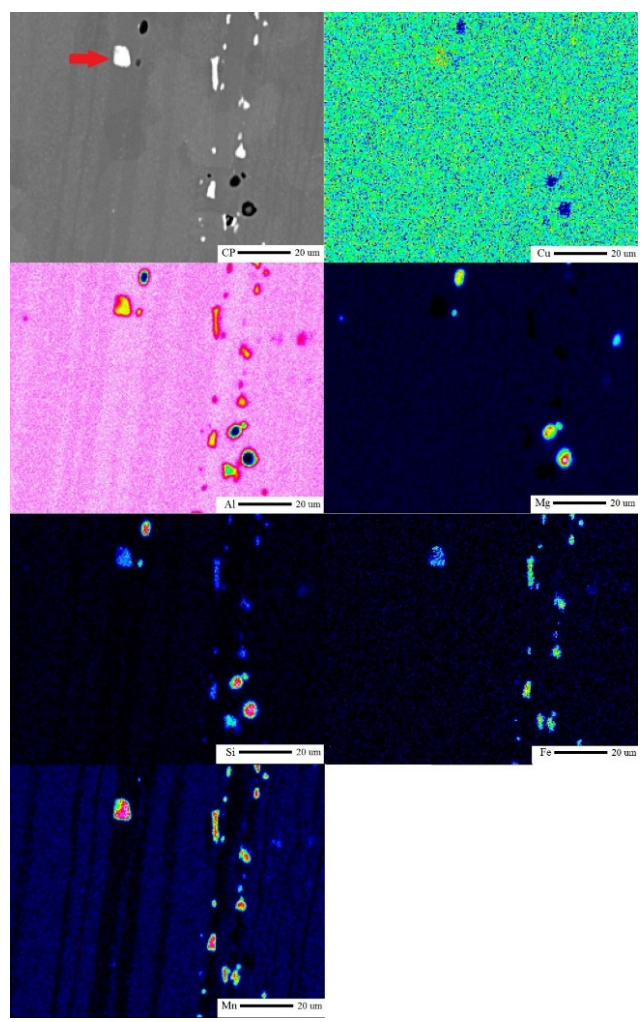

(b)

Figure 6. SEM photo and alloying elements mappings obtained from (a) T6 sample and (b) CFT6a sample. 
The $Q$ phase, $\mathrm{Al}(\mathrm{Mn}, \mathrm{Fe}) \mathrm{Si}$, and $\mathrm{Mg}_{2} \mathrm{Si}$ (larger than $80 \mathrm{~nm}$ ) contained in the aluminum alloy sample are non-shearable particles in the $\alpha$-Al matrix [25]. Therefore, the T6 samples gained high strength. By contrast, the CFT6a samples contained $\mathrm{Al}(\mathrm{Mn}, \mathrm{Fe}) \mathrm{Si}, \mathrm{Mg}_{2} \mathrm{Si}$, fine $\mathrm{CuMgSi}$, and $\mathrm{Cu}_{9} \mathrm{Al}_{4}$ precipitates The fine $\mathrm{Mg}_{2} \mathrm{Si}$ or $\mathrm{CuMgSi}$ and $\mathrm{Cu}_{9} \mathrm{Al}_{4}$ precipitates are shearable. Figure 7 illustrates the dislocations (marked as 1-1 and 2-2) intersected with two fine precipitates. In addition, the SP/IMC particle counts (Figure 2) were lower in the matrix of the CFT6a samples. As a result, the CFT6a sample had decreased numbers of barrier sites for tangling dislocations to reduce strength but enhance elongation.

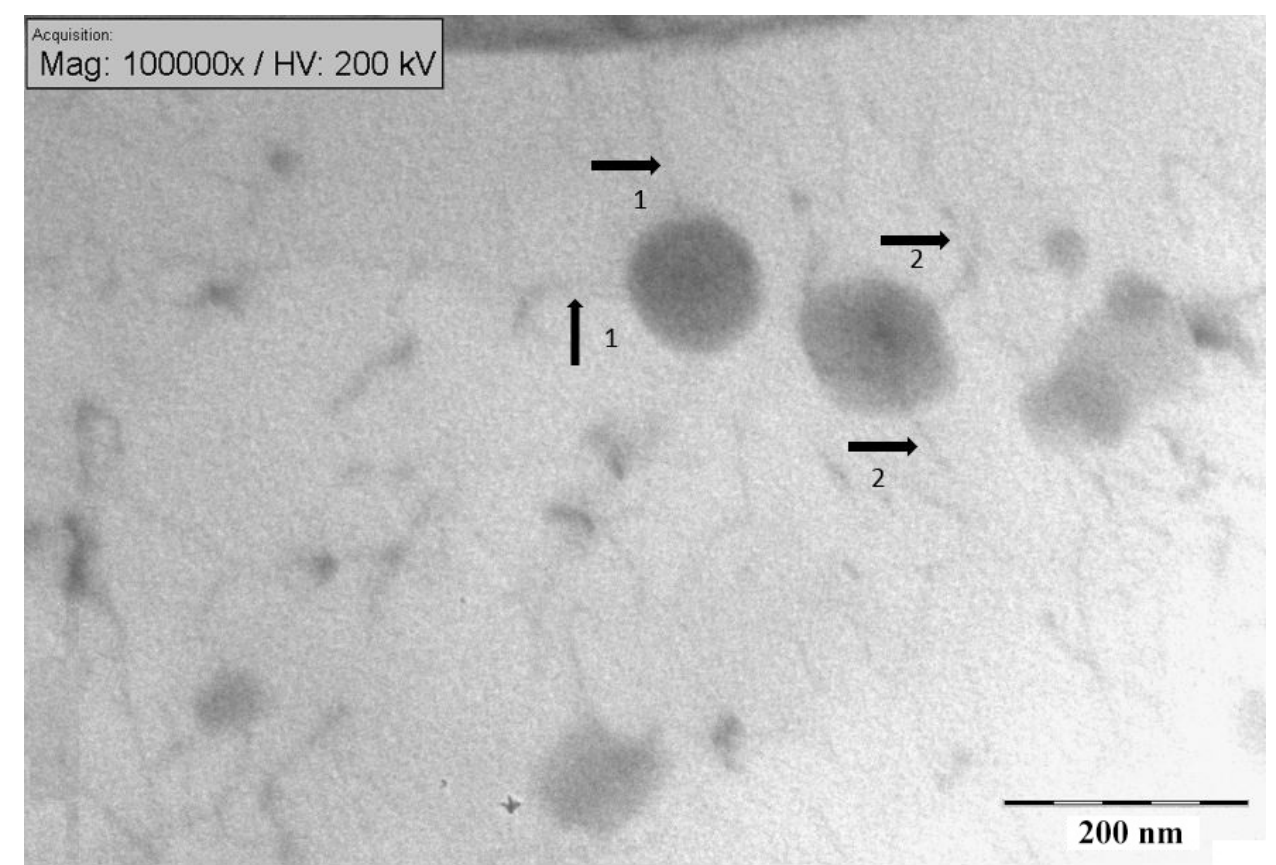

Figure 7. TEM photo shows the intersection of dislocation 1-1 and 2-2 with two fine precipitates in the matrix of CFT6a sample, respectively.

Table 3 compares the surface roughness of T6 and CFT6a samples before and after anodization/sealing. Compared with the samples without anodization, these anodized and sealed samples showed an approximately $8 \%-10 \%$ reduction in elongation. Such a decrease is likely caused by the dissolution of SP/IMC at the film/matrix interface leading to degrade surface roughness and elongation. Before anodization, the surface roughness of the T6 and CFT6a sample was approximately $0.07(0.04) \mu \mathrm{m}$; after anodization and sealing, the surface roughness became $0.16(0.03)$ and $0.13(0.06) \mu \mathrm{m}$.

Table 3. Measured surface roughness of different samples before and after anodization.

\begin{tabular}{cc}
\hline Sample & Surface Roughness $(\mu \mathrm{m})$ \\
\hline T6; CFT6a & $0.07(0.04)$ \\
T6-A & $0.16(0.03)$ \\
CFT6a-A & $0.13(0.06)$ \\
\hline
\end{tabular}

Note: the deviations are listed in parentheses.

\subsection{Fatigue and Corrosion Tests}

Applying the cryoforge before the solution treatment reduced the SP/IMC particle counts and transformed the $Q$ phase into nanoscale $\mathrm{CuMgSi}$ and $\mathrm{Cu}_{9} \mathrm{Al}_{4}$ precipitates, which reduced UTS and YS but increased elongation. Figure 8 shows that both the T6 and CFT6a samples obtained fatigue 
strength of $180 \mathrm{MPa}$ at $1 \times 10^{7}$ life cycles. As shown in Figure 3a,c, we found that cyclic loading functioned to shift the peak of relative frequency from the misorientation angle of $40^{\circ}-45^{\circ}$ to $45^{\circ}-50^{\circ}$, and increase some grain boundaries at angles of $10^{\circ}-20^{\circ}$. During cyclic loading, shear stress drove part of the dislocations to conduct polygonization and/or reorganization.

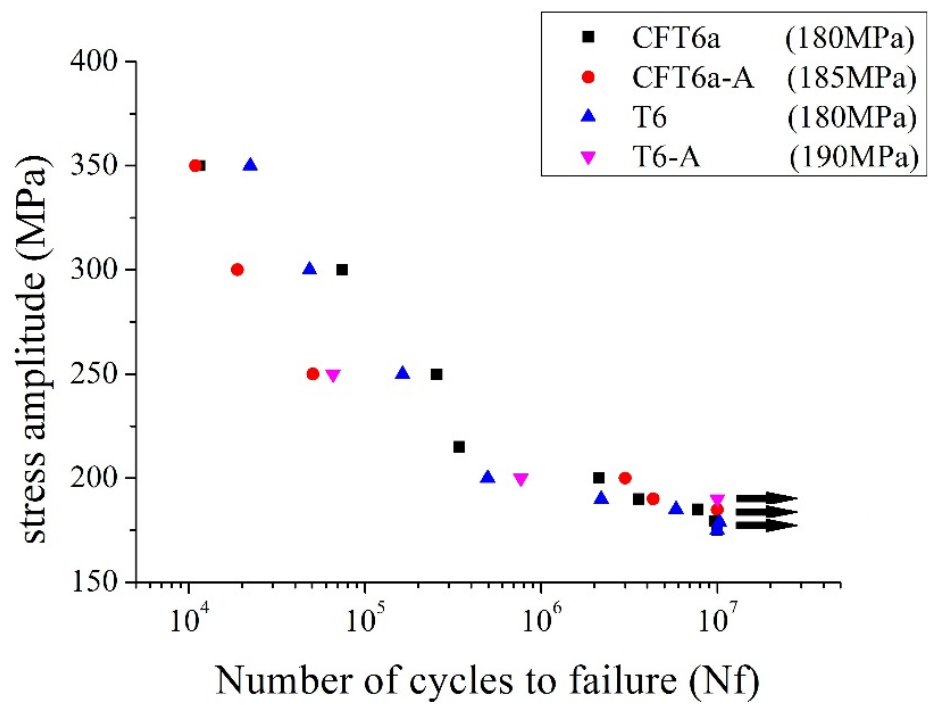

Figure 8. S-N curves for different samples; including T6 and CFT6a with/without anodization/sealed treatment; "A" represented anodization/sealed sample.

Figure 9a,b show the fractured surface of the T6 and CFT6a samples, both of which were subjected to $185 \mathrm{MPa}$ and which performed $5.8 \times 10^{6}$ and $7.7 \times 10^{6}$ life cycles, respectively. The CFT6a sample exhibited narrower striation spacing than did the T6 samples and achieved a longer fatigue life. The T6 sample obtained fracture steps, as revealed in Figure 9a, which can be attributed to the $Q$ phase located at or near grain boundaries that served to strengthen the grain boundaries [22,26]. Increasing fine precipitates in the matrix of the CFT6a sample likely more effectively to consume the crack propagation energy and thus slightly enhanced the life cycles.

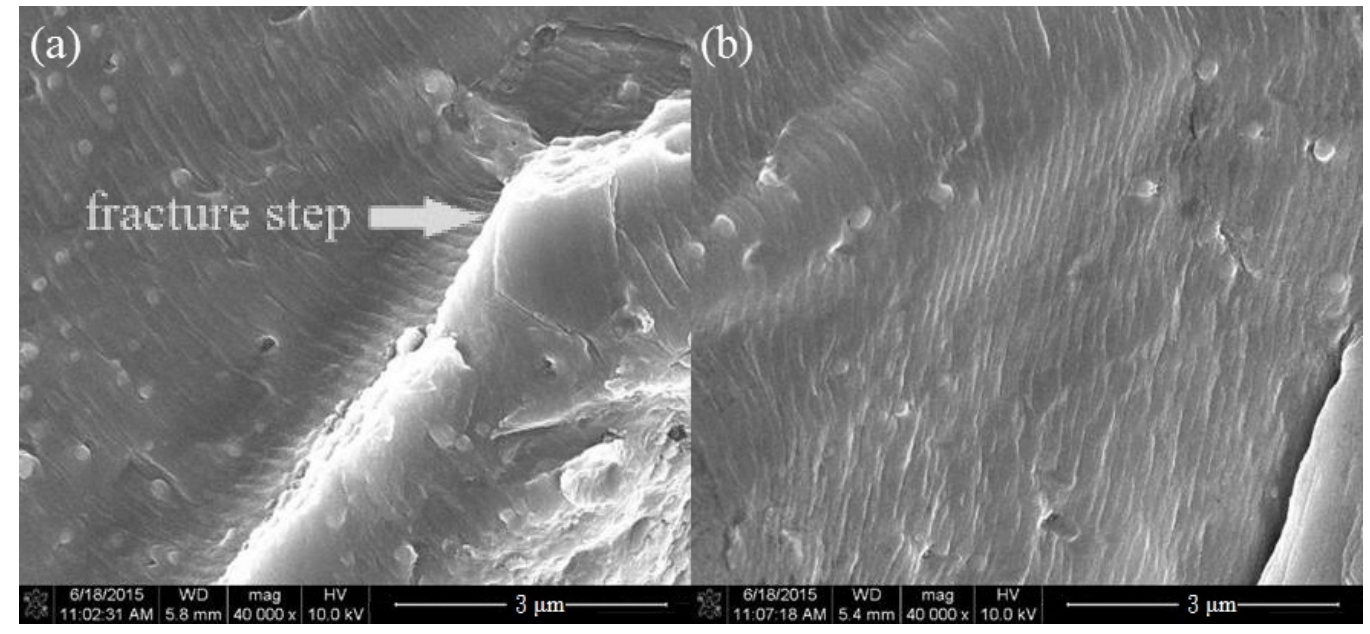

Figure 9. Fracture surface prepared from (a) T6; (b) CFT6a samples; both subjected to $185 \mathrm{MPa}$ and fractured at $5.8 \times 10^{6}$ and $7.7 \times 10^{6}$ life cycles, respectively.

The SP/IMC particles were small to be less than $17 \mu \mathrm{m}$. Anodization did not yield the deteriorated effect of reducing fatigue strength. The two anodized and sealed samples (T6-A and CFT6a-A) showed 
similar fatigue strength (185-190 MPa) at $1 \times 10^{7}$ life cycles as did those without anodization and sealing (180 MPa).

The polarization curves for all the samples with and without sealed anodic aluminum oxide (AAO) films are shown in Figure 10. The corrosion behavior of the samples was affected by the constituent phases of each. The T6 samples contained $\mathrm{AlCuMgSi}, \mathrm{Al}(\mathrm{FeMn}) \mathrm{Si}$, and $\mathrm{Mg}_{2} \mathrm{Si}$ phases, whereas the CFT6a samples acquired mainly $\mathrm{Al}(\mathrm{FeMn}) \mathrm{Si}$ and $\mathrm{Mg}_{2} \mathrm{Si}$ phases as well as some $\mathrm{CuMgSi}$ and $\mathrm{Cu}_{9} \mathrm{Al}_{4}$ precipitates. $\mathrm{Mg}_{2} \mathrm{Si}$ is anodic relative to the aluminum matrix, but $\mathrm{Al}(\mathrm{FeMn}) \mathrm{Si}$ and $\mathrm{AlCuMgSi}$ are cathodic. The $\mathrm{Cu}-\mathrm{Al}$ precipitates are more vulnerable to attack during the immersion test, compared with the $Q$ phase [23]. The CFT6a samples exhibited slightly inferior $E_{\text {corr }}(-1.0 \mathrm{~V})$ and $I_{\text {corr }}\left(4.7 \times 10^{-6} \mathrm{~A} / \mathrm{cm}^{2}\right)$ than the T6 sample did $\left(-0.93 \mathrm{~V}\right.$ and $2.6 \times 10^{-6} \mathrm{~A} / \mathrm{cm}^{2}$, respectively).

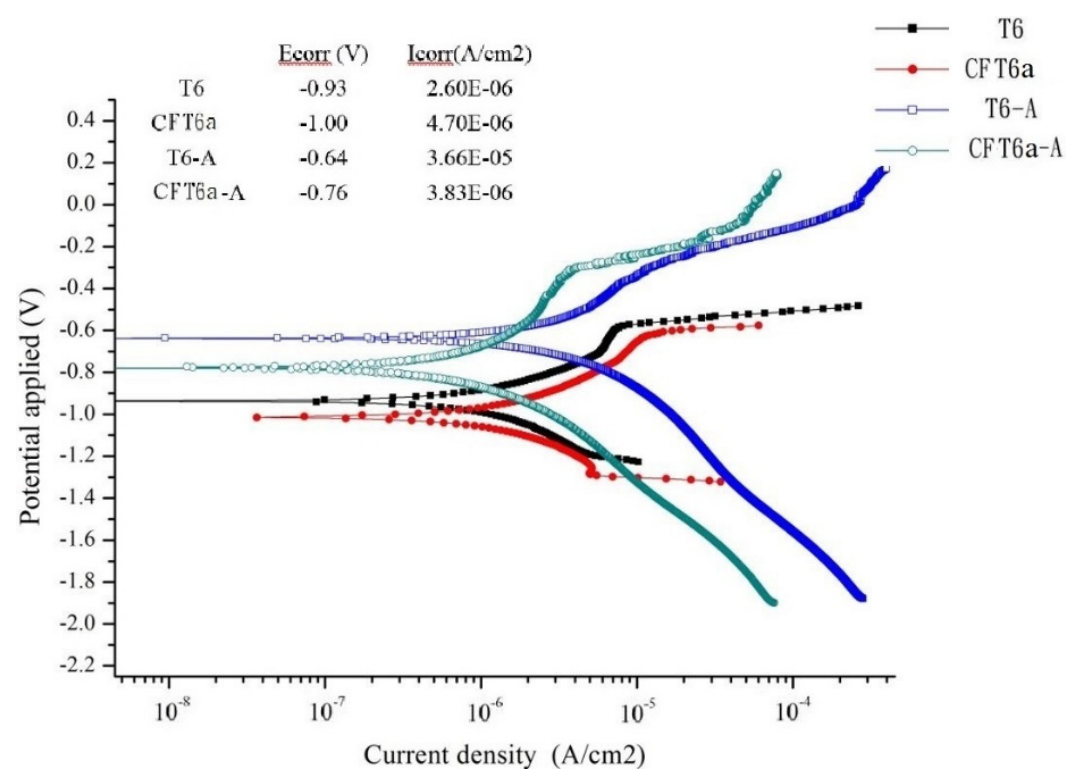

Figure 10. Polarization curves obtained from immersion tests of T6 and CFT6a samples with/without anodization/sealing treatment.

After anodization and sealing, the anodized films on the aluminum alloy samples contained mainly amorphous alumina and a few hydrated alumina [27]. These AAO films could significantly enhance the corrosion resistance of the aluminum alloys [28]. Therefore, the anodized films deposited on the T6 and CFT6 samples improved $E_{\text {corr }}$ from $(-0.9$ to $-1.0 \mathrm{~V})$ to $(-0.64$ to $-0.76 \mathrm{~V})$.

Affected by a greater number of coarse SP/IMC (Table 2) and/or a higher particle population, the anodized and sealed film on the T6 sample was entrapped with particles along with air pockets, as shown in Figure 11a. By contrast, the film on the CFT6a sample is relatively sound with few trapped particles; see Figure 11b. The trapped particles could function as corrosion channels to accelerate chloride attacks. Therefore, the anodized and sealed T6 sample obtained a higher current density $\left(I_{\text {corr }}\right.$ of $\left.3.6 \times 10^{-5} \mathrm{~A} / \mathrm{cm}^{2}\right)$ than did the anodized and sealed CFT6a sample $\left(I_{\text {corr }}\right.$ of $\left.3.8 \times 10^{-6} \mathrm{~A} / \mathrm{cm}^{2}\right)$.

The dissolution of SP/IMC at the film-matrix interface drove aluminum and magnesium ions to move toward electrolytes leaving the Si particles remaining in the film, as shown in Figure 11c [27]. Consequently, the anodized and sealed T6 sample obtained inferior corrosion current density to the bare T6 sample $\left(3.6 \times 10^{-5} \mathrm{~A} / \mathrm{cm}^{2}\right.$ vs. $\left.2.6 \times 10^{-6} \mathrm{~A} / \mathrm{cm}^{2}\right)$. Decreasing SP/IMC particle size and counts also reduced the size and counts of the Si particles that remained in the anodized film to undergo a minor change in corrosion current density $\left(4.7 \times 10^{-6}\right.$ vs. $\left.3.86 \times 10^{-6} \mathrm{~A} / \mathrm{cm}^{2}\right)$ in the bare CFT6a and anodized/sealed CFT6a samples. 


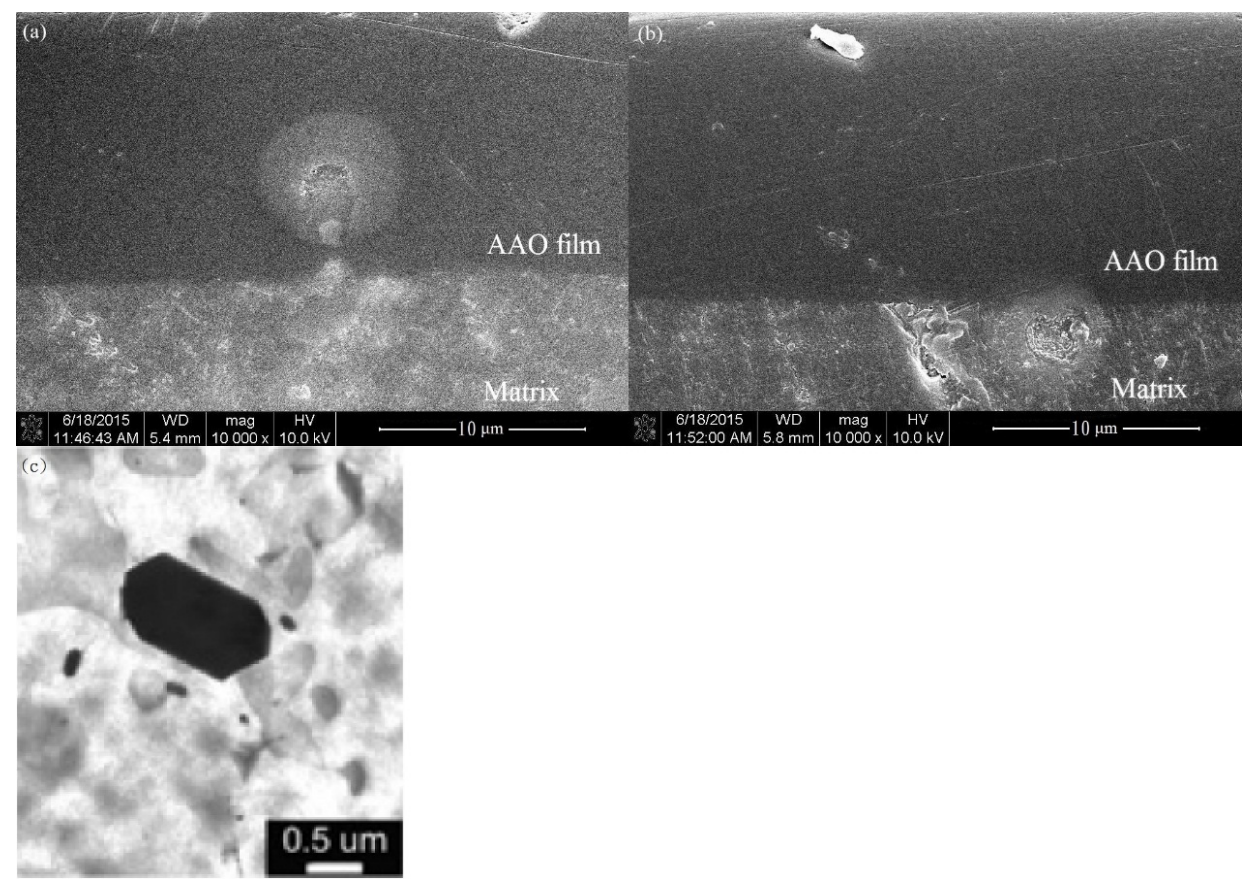

Figure 11. SEM photos show the cross-section of deposited anodized/sealed films on (a) T6 sample;

(b) CFT6a sample; and (c) anodized/sealed 6063-T6 samples [27].

\section{Conclusions}

Adding cryoforging to the process changed the microstructure and mechanical properties of the AA6066-T6 alloy samples; specifically, it decreased SP/IMC particle counts and reduced the $Q$ phase but increased fine $\mathrm{CuMgSi}$ and $\mathrm{Cu}_{9} \mathrm{Al}_{4}$ precipitates in the matrix of the CFT6a sample. As a result, the tensile property of elongation was increased by approximately $34 \%$ comparing with $\mathrm{T} 6$ sample. The anodized and sealed AAO film on the CFT6a sample improved its corrosion resistance but decreased its elongation by approximately $10 \%$ (from $14.2 \%$ to $12.7 \%$ ).

Acknowledgments: We gratefully acknowledge the financial support from the Ministry of Science and Technology of the Republic of China (MOST 103-2221-E-008-026-MY2). Many thanks also to National Central University for providing the SEM and TEM tests and to National Sun-Yat Sen University for the EBSD analysis.

Author Contributions: Hwa-Sheng Yong and Wen-Nong Hsu ran experiments of this study and did OM, SEM, TEM observation and EBSD analyses. Main contribution also included experimental data collection. All authors provided equal contribution.

Conflicts of Interest: The authors declare no conflict of interest.

\section{References}

1. Wang, Y.M.; Ma, E.; Chen, M.W. Enhanced tensile ductility and toughness in nanostructured Cu. Appl. Phys. Lett. 2002, 80, 2395-2397. [CrossRef]

2. Rangaraju, N.; Raghuram, T.; Krishna, B.V.; Rao, K.P.; Venugopal, P. Effect of cryo-rolling and annealing on microstructure and properties of commercially pure aluminium. Mater. Sci. Eng. A Struct. 2005, 398, $246-251$. [CrossRef]

3. Chen, Y.J.; Roven, H.J.; Gireesh, S.S.; Skaret, P.C.; Hjelen, J. Quantitative study of grain refinement in Al-Mg alloy processed by equal channel angular pressing at cryogenic temperature. Mater. Lett. 2011, 65, 3472-3475. [CrossRef]

4. Lee, Y.B.; Shin, D.H.; Park, K.T.; Nam, W.J. Effect of annealing temperature on microstructures and mechanical properties of a $5083 \mathrm{Al}$ alloy deformed at cryogenic temperature. Scr. Mater. 2004, 51, 355-359. [CrossRef]

5. Panigrahi, S.K.; Jayagathan, R. A study on the mechanical properties of cryorolled Al-Mg-Si alloy. Mater. Sci. Eng. A Struct. 2008, 480, 299-305. [CrossRef] 
6. Panigrahi, S.K.; Jayagathan, R.; Chawla, V. Effect of cryorolling on microstructure of Al-Mg-Si alloy. Mater. Lett. 2008, 62, 2626-2639. [CrossRef]

7. Panigrahi, S.K.; Jayagathan, R. Development of ultrafine-grained Al 6063 alloy by cryorolling with the optimized initial heat treatment conditions. Mater. Des. 2011, 32, 2172-2180. [CrossRef]

8. Krishna, K.G.; Sivaprasad, K.; Venkateswarlu, K.; Kumar, K.C.H. Microstructural evolution and aging behavior of cryorolled Al-4Zn-2Mg alloy. Mater. Sci. Eng. A Struct. 2012, 535, 129-135. [CrossRef]

9. Das, P.; Jayaganthan, R.; Singh, I.V. Tensile and impact-toughness behavior of cryorolled Al 7075 alloy. Mater. Des. 2011, 32, 1298-1305. [CrossRef]

10. Panigrahi, S.K.; Jayaganthan, R. Effect of ageing on microstructure and mechanical properties of bulk, cryorolled, and room temperature rolled Al 7075 alloy. J. Alloy. Compd. 2011, 509, 9609-9016. [CrossRef]

11. Yin, J.; Lu, J.; Ma, H.; Zhang, P. Nanostructural formation of fine grained aluminum alloy by severe plastic deformation at cryogenic temperature. J. Mater. Sci. 2004, 39, 2851-2854. [CrossRef]

12. Krishna, K.G.; Sivaprasad, K.; Narayanana, T.S.N.S.; Kumar, K.C. Localized corrosion of an ultrafine grained $\mathrm{Al}-4 \mathrm{Zn}-2 \mathrm{Mg}$ alloy produced by cryorolling. Corros. Sci. 2012, 60, 82-89. [CrossRef]

13. Shanmugasundaram, T.; Murty, B.S.; Sarma, V.S. Development of ultrafine grained high strength Al-Cu alloy by cryorolling. Scr. Mater. 2006, 54, 2013-2017. [CrossRef]

14. Rao, P.N.; Jayaganthan, R. Effects of warm rolling and ageing after cryogenic rolling on mechanical properties and microstructure of $\mathrm{Al} 6061$ alloy. Mater. Des. 2012, 39, 226-233.

15. Huang, Y.S.; Shih, T.S.; Chou, J.H. Electrochemical behavior of anodized AA7075-T73 alloys affected by matrix structures. Appl. Surf. Sci. 2013, 283, 249-257. [CrossRef]

16. ASTM B557-15, Standard Test Methods for Tension Testing Wrought and Cast Aluminum-and Magnesium-Alloy Products; ASTM International: West Conshohocken, PA, USA, 2015. [CrossRef]

17. JIS Z2274, Method of Rotating Bending Fatigue Testing of Metals; Japanese Standards Association: Tokyo, Japan, 1978.

18. Shih, T.S.; Lee, T.H.; Jhou, Y.J. The effects of anodization treatment on the microstructure and fatigue behavior of 7075-T73 aluminum alloy. Mater. Trans. 2014, 55, 1280-1285. [CrossRef]

19. Kim, H.J.; Lee, J.Y.; Paik, K.W.; Koh, K.W.; Won, J.; Choe, S.; Lee, J.; Moon, J.T.; Park, Y.J. Effects of Cu/Al intermetallic compound (IMC) on copper wire and aluminum pad bondability. IEEE Trans. Pack. Technol. 2003, 26, 367-374.

20. Du, Y.; Chang, Y.A.; Huang, B.; Gong, W.; Jin, Z.; Xu, H.; Yuan, Z.; Liu, Y.; He, Y.; Xie, F.Y. Diffusion coefficients of some solutes in fcc and liquid Al: Critical evaluation and correlation. Mater. Sci. Eng. A Struct. 2003, 363, 140-151. [CrossRef]

21. Matsuda, K.; Teguri, D.; Sato, T.; Uetani, Y.; Ikeno, S. Cu Segregation around Metastable Phase in Al-Mg-Si Alloy with Cu. Mater. Trans. 2007, 48, 967-974. [CrossRef]

22. Svenningsen, G.; Larsen, M.H.; Walmsley, J.C.; Nordlien, J.H.; Nisancioglu, K. Effect of artificial aging on intergranular corrosion of extruded AlMgSi alloy with small Cu content. Corros. Sci. 2006, 48, 1528-1543. [CrossRef]

23. Vieira, A.C.; Pinto, A.M.; Rocha, L.A.; Mischler, S. Effect of $\mathrm{Al}_{2} \mathrm{Cu}$ precipitates size and mass transport on the polarisation behaviour of age-hardened Al-Si-Cu-Mg alloys in $0.05 \mathrm{M} \mathrm{NaCl}$. Electrochim. Acta 2011, 56, 3821-3828. [CrossRef]

24. Li, Y.J.; Muggerud, A.M.F.; Olsen, A.; Furu, T. Precipitation of partially coherent $\alpha$-Al(Mn,Fe)Si dispersoids and their strengthening effect in AA 3003 alloy. Acta Mater. 2012, 60, 1004-1014. [CrossRef]

25. Cabibbo, M. Microstructure strengthening mechanisms in different equal channel angular pressed aluminum alloys. Mater. Sci. Eng. A Struct. 2013, 560, 413-432. [CrossRef]

26. Zhaia, T.; Jianga, X.P.; Lia, J.X.; Garratt, M.; Bray, G.H. The grain boundary geometry for optimum resistance to growth of short fatigue cracks in high strength Al-alloys. Int. J. Fatigue 2005, 27, 1202-1209. [CrossRef]

27. Huang, Y.S.; Shih, T.S.; Wu, C.E. Electrochemical behavior of anodized AA6063-T6 alloys affected by matrix structures. Appl. Surf. Sci. 2013, 264, 410-418. [CrossRef]

28. Shih, T.S.; Chiu, Y.W. Corrosion resistance and high-cycle fatigue strength of anodized/sealed AA7050 and AA7075 alloys. Appl. Surf. Sci. 2015, 351, 997-1003. [CrossRef]

(C) 2016 by the authors; licensee MDPI, Basel, Switzerland. This article is an open access article distributed under the terms and conditions of the Creative Commons by Attribution (CC-BY) license (http://creativecommons.org/licenses/by/4.0/). 